\title{
EGRESSOS COMO FONTE DE INFORMAÇÃO À GESTÃO DOS CURSOS DE CIÊNCIAS CONTÁBEIS*
}

\author{
ANA CRISTINA ZENHA LOUSADA \\ Professora Ms. da Universidade do Vale do Itajaí - SC \\ E-mail: crislousada@itj.viacabocom.com.br

\section{GILBERTO DE ANDADRE MARTINS} \\ Professor Titular do Depto. de Contabilidade e Atuária da FEA/USP - SP \\ E-mail:martins@usp.br
}

\section{RESUMO}

Este estudo tem como objetivo mostrar a importância do planejamento e desenvolvimento de sistemas de acompanhamento de egressos como um dos mecanismos que permita às Instituições de Ensino Superior (IES) a contínua melhoria de todo o planejamento e operação dessas organizações, particularmente do processo de ensino aprendizagem. Sendo uma das finalidades das IES inserir na sociedade diplomados aptos para o exercício profissional, deve ter ela retorno quanto a indicadores da qualidade dos profissionais que vem formando, principalmente no que diz respeito à qualificação para o trabalho. Para cumprir o objetivo, tornou-se necessário proceder-se a verificações empíricas no que tange às percepções e motivações dos dirigentes das IES, particularmente dos Cursos de Ciências Contábeis, a fim de se conseguirem elementos da realidade para compor a descrição e compreensão do fenômeno sob investigação. Os resultados apontaram o reconhecimento da necessidade de institucionalização e prática do acompanhamento dos egressos nas IES, visando à melhoria da qualidade dos serviços educacionais prestados.

Palavras-chave: Egressos; Instituições de Ensino Superior; Ensino-aprendizagem.

\begin{abstract}
This study aims to show the importance of planning and developing alumni follow-up systems as a tool to allow for the continuous improvement of the whole planning and operation of Higher Education Institutions - IES, particularly of the teachinglearning process. As one of the aims of IESs is to provide society with graduates who are ready for the professional market, they should receive feedback from their former students through quality indicators, particularly concerning the qualification to work. The perceptions and motivations of IESs managers, particularly those of Accountancy Programs, were subject to empirical examination, in order to gather elements from reality with a view to the description and understanding of the phenomenon under study. The results revealed that the IESs recognize the need to institutionalize and practice alumni followup to improve the quality of the educational services they deliver.
\end{abstract}

Keywords: Alumni; Higher Education Institutions; Teaching-learning. 


\section{CONTEXTUALIZAÇÃO}

É indiscutível a forte relação existente entre Universidade e sociedade. Segundo Martins (1986), dado o caráter dinâmico da sociedade e a própria condição intrínseca da natureza humana que, por sua capacidade criativa, busca contínuo aperfeiçoamento, necessita-se, cada vez mais, de Instituições de Ensino preocupadas com o seu meio externo, procurando servir e influenciar esse meio.

Se uma das finalidades da Universidade é inserir na sociedade diplomados aptos para o exercício profissional, deve ter ela retorno quanto à qualidade desses profissionais que vem formando, principalmente no que diz respeito à qualificação para o trabalho.

Nesse aspecto, a integração Universidade/ mercado de trabalho é fundamental. Nessa interação, destaca-se o egresso - aquele que efetivamente concluiu os estudos, recebeu o diploma e está apto a ingressar no mercado de trabalho - como fator de destaque e fonte de informação à Instituição de Ensino Superior (IES) que o formou.

Conforme Éden (in: MACHADO, 2001, p. 11):

A visão empresarial sobre uma instituição de ensino é, principalmente, balizada pela formação discente que ela fornece, percebida através dos estágios e/ou egressos. Uma avaliação positiva estende a competência para os seus docentes e, em decorrência, para a instituição como um todo, numa espécie de credenciamento. Do lado acadêmico, é fundamental estender o papel exercido pelo aluno ou egresso, como elemento básico para o processo de interação.

Existem poucas informações sobre os egressos dos cursos de Ciências Contábeis em nível de avaliação do curso, contribuição da formação acadêmica para a vida profissional, absorção pelo mercado de trabalho, satisfação profissional, perfil do profissional etc., informações essas necessárias para uma avaliação da formação obtida e, conseqüentemente, para a melhoria do ensino. Essa "falta de informação" é, fortemente, derivada da inexistência de sistemas de acompanhamento de egressos por parte das IES.

As IES não obtêm o feedback necessário à avaliação do ensino ofertado, deixando de realizar, periodicamente, as mudanças necessárias em seus currículos e processos de ensino-aprendizagem dos conteúdos ministrados, visando ao preenchimento de lacunas eventualmente existentes, perdendo oportunidades, inclusive, de obter retorno positivo dessa retroalimentação como, por exemplo, utili- zação dos resultados como forma de aperfeiçoar ações de marketing institucional.

As rápidas mudanças ocorridas na sociedade como, por exemplo, a globalização da economia, os avanços tecnológicos, o crescimento da oferta de cursos superiores e as novas exigências do mercado de trabalho com relação à preparação dos profissionais, exigem que as IES desenvolvam nos profissionais que formam, além das capacidades técnicas, uma visão multidisciplinar, ultrapassando a complexidade do conhecimento científico. Nesse sentido, Castro discorre:

Formar cidadãos aptos a exercerem atividades produtivas ainda é um desafio em muitos países como o Brasil. Mas é preciso mais que isso. É preciso formar cidadãos capazes para desempenhar atividades que sequer existem atualmente. Isso significa ensinar conteúdos e habilidades úteis no presente, mas também ensinar a aprender no futuro, fora da escola convencional. (CASTRO in: MEHEDFF, 1999, p. 5).

Para que isso aconteça, é necessário que as IES introduzam em seus currículos ajustes constantes, com o intuito de propiciar aos profissionais, formados por ela, conhecimentos, habilidades e atitudes para exercerem atividades e funções em uma ampla gama de processos, capazes de resolver problemas inerentes à sua área de formação e superar situações contingentes de maneira segura.

É, pois, imprescindível saber o que os egressos pensam a respeito da formação recebida para se proceder a ajustes em todas as partes do sistema de ensino ofertado. Além disso, conhecer o que fazem como profissionais e cidadãos e suas adequações aos setores em que atuam, possibilita uma reflexão crítica sobre a formação e sua relação com as necessidades do mercado de trabalho. É interessante, também, conhecer a trajetória profissional e acadêmica, ou seja, em quanto tempo o egresso se estabiliza no mercado, qual o seu poder decisório, competências, autonomia e perspectivas, bem como o trajeto percorrido através de cursos após a graduação.

\subsection{Problema de pesquisa}

Para que uma IES possa efetuar pesquisas sobre seus ex-alunos é necessário estabelecer um canal de comunicação entre ambos. Entendese que esse canal se dê através da construção de uma pesquisa longitudinal de acompanhamento de egressos. Não se trata da confecção de pesquisas isoladas e, sim, de uma estrutura que possa, efe- 
tivamente, acompanhar de forma sistemática, pelo menos durante um período de tempo predeterminado, a evolução da trajetória profissional do egresso no "mundo do trabalho".

Nesse contexto, pretende-se buscar evidências que possam responder à seguinte questão: qual a importância do desenvolvimento de sistemas de acompanhamento de egressos como um mecanismo que permita a melhora contínua da qualidade da gestão dos serviços educacionais prestados?

É importante, ainda, investigar qual é a visão que os dirigentes das IES, na figura de seus diretores, coordenadores de curso, chefes de departamentos etc., têm acerca do acompanhamento de egressos. Para que um sistema funcione e apresente resultados, torna-se necessário um efetivo apoio por parte dos dirigentes das Instituições de Ensino no tocante a "querer tomar conhecimento" da qualidade do profissional que vêm formando.

$\mathrm{Na}$ visão de Schwartzman e Castro (1991), o estudo de egressos recupera, de fato, várias questões do estudo de alunos, particularmente as ligadas: à qualidade do ensino e adequação dos currículos à situação profissional; à origem dos projetos profissionais e a sua consistência em relação à situação profissional de fato.

\section{REFERENCIAL TEÓRICO}

\subsection{Avaliação nas Instituições de Ensino Superior}

Segundo Both (1999), o momento histórico em que vive a sociedade brasileira na busca de cada vez melhores e mais adequadas formas de investigação da realidade educacional e da formação de quadros que dêem conta de interpretar essa realidade, aponta para a necessidade de implantação de sistemas efetivos de avaliação institucional dos três graus de ensino e, especialmente, do ensino de $3^{\circ}$ grau.

As Universidades são depositárias das esperanças sociais de grande parte da população, que espera e cobra resultados, benefícios sociais e culturais efetivos das IES. Tais Instituições, para darem cumprimento a essa tarefa, necessitam ter uma consciência clara de suas potencialidades e limites, bem como contar com mecanismos capazes de indicar, com clareza, as diretrizes e metas futuras.

Cabe a cada IES implementar o processo avaliativo que melhor atenda às suas características e expectativas. Nesse contexto, a avaliação institucional, certamente, contribui para que a IES repense as suas práticas administrativas, técnicas e pedagógicas, de forma crítica e comprometida, refletindo sobre o seu papel na sociedade como promotora e socializadora do saber capaz de compreender e de modificar a realidade.

De acordo com Souza (1999), o objetivo principal da avaliação das Instituições de Ensino Superior é promover a melhoria do ensino e da aprendizagem. A missão, o seu propósito e seus objetivos é que determinam o tipo de avaliação que deve ser conduzido. A avaliação global da eficiência poderá ser feita através do exame e da análise dos dados contendo os resultados tanto dos aspectos operacionais como acadêmicos dos diversos cursos, das diversas unidades, departamentos e programas da Instituição. Esses componentes incluem a parte administrativa, as relações com a comunidade na qual a Instituição está inserida e o clima institucional.

Como em qualquer tipo de avaliação, a de cursos é, necessariamente, uma estratégia voltada para a ação.

No caso específico da avaliação de cursos, procura-se atingir dois propósitos básicos na visão de Franco (2000, p.4):

a) o primeiro diz respeito à avaliação de processo que busca corrigir distorções desde o planejamento até o desenvolvimento e evolução dos cursos;

b) o segundo refere-se à certificação ou validade dos cursos. Ou seja, procura-se investigar quantos se certificaram e com que qualidade.

A avaliação de cursos pressupõe, pelo menos, duas modalidades:

- Avaliação interna ou auto-avaliação: desenvolvida pelos integrantes da própria Instituição e coordenada por comissões responsáveis.

- Avaliação externa: a ser feita por especialistas de diferentes áreas do conhecimento, mas não diretamente vinculados à Instituição que está sendo avaliada. O Exame Nacional de Cursos - ENC e o Exame de Suficiência do Conselho Federal de Contabilidade estão enquadrados nessa classificação.

$\mathrm{Na}$ opinião de Franco (2000), ambas as modalidades são valiosas. A primeira permite um desenvolvimento processual, contínuo e sistemático da avaliação de cursos. A outra propicia "um olhar de fora" e, desde que realizada por especialistas qualificados, contribui com ganhos significativos para a análise e interpretação dos resultados da avaliação. 
Segundo Both (1999), a avaliação institucional visualiza o seu desenvolvimento com base em duas grandes variáveis: a quantitativa e a qualitativa. A variável quantitativa envolve, principalmente, um levantamento de dados de ordem numérica da IES com relação a:

- alunos;

- professores;

- pessoal técnico e administrativo;

- dados de infra-estrutura e apoio.

A variável qualitativa, ainda na visão de Both, compreende seis componentes:

- avaliação do desempenho da IES por ex-alunos;

- avaliação do desempenho dos serviços administrativos da IES;

- avaliação do desempenho da IES por representantes da sociedade;

- identificação da realidade sócio-educacional dos alunos da IES;

- avaliação do desempenho do ensino da IES por alunos e professores;

- avaliação do desempenho da pós-graduação da IES em nível Lato Sensu (especialização).

É bastante expressivo o universo a ser atingido pelo processo de avaliação institucional. Tal fato permite uma visão praticamente global da Instituição, tanto em termos quantitativos quanto qualitativos, o que facilita o redimensionamento da política e dos planos da Universidade e para sua área de abrangência.

A avaliação visa à qualidade como questão, inclusive, de sobrevivência institucional. A visualização da realidade da IES, mediante o processo de auto-avaliação - avaliação interna - e avaliação externa, permite a tomada de decisão ponderada por parte dos administradores para o redimensionamento dos desvios que ora se apresentam.

O estudo de acompanhamento de egressos pode ser inserido nesse contexto da avaliação institucional, como um componente que irá auxiliar no apontamento da realidade qualitativa da IES, como uma das formas de avaliação de produtos ou resultados, ou seja, vai conferir significado à avaliação dos cursos, quanto a sua respeitabilidade, desempenho, qualidade e, até mesmo, quanto ao seu prestígio externo.

Dessa forma, Both (1999, p. 152) discorre:

A avaliação da Universidade por ex-alunos torna-se um dos componentes de fundamental importância, tendo em vista estar percebendo o aluno que passou pela Instituição a real contribuição que seu curso lhe propiciou para o desempenho de suas funções e atividades no dia-a-dia.

Entende-se ser o egresso um ponto expressivo de referência para a avaliação do ensino da Universidade, visto estar ele colocando em prática, profissionalmente, o aprendizado que lhe foi proposto na IES.

\subsection{A integração Universidade/ mercado de trabalho}

A Universidade desempenha um papel de geradora e disseminadora de conhecimento e sua relação com o setor produtivo deve ser na busca da promoção do desenvolvimento econômico e social.

Segundo Kunz (1999), a Universidade tem como função principal formar um cidadão, desenvolvendo sua consciência crítica, contribuindo para o desenvolvimento humano, para o bem-estar da sociedade, para o bom funcionamento das relações sociais, para a reflexão dos valores. Em resumo, os objetivos da Universidade são mais amplos do que aqueles esperados pela maioria dos agentes presentes no mercado de trabalho. Por outro lado, a Universidade não pode se manter independente daquilo que lhe dá a razão de existir: a formação de novos profissionais.

Na visão de Garcias (1999), a integração entre as Universidades e as empresas deve ser uma via de mão dupla, caracterizada por um fluxo contínuo de troca de experiências e informações. A Universidade tem a responsabilidade social de ser uma organização de vanguarda no desenvolvimento e disseminação de novos conhecimentos. Mas, para que suas pesquisas tenham resultados efetivos, devem estar vinculadas à realidade da qual fazem parte.

Contudo, apesar da interação Universidade/ Empresa ser uma importante ferramenta para a resolução de problemas ligados ao setor produtivo, alguns desafios persistem e dificultam as ações pertinentes a esse processo. Na opinião de Stainsack (1999, p.119), seriam os seguintes:

a) Descrença do setor produtivo em relação à Universidade, na qual as Instituições de Ensino Superior são extremamente teóricas na solução de problemas relativamente práticos gerados na indústria; de outro lado, as Instituições de Ensino reclamam do imediatismo que as empresas reivindicam na solução de seus problemas; 
b) Falta de capital e investimento por parte das Universidades para geração de pesquisas científicas e tecnológicas que contribuam para o setor produtivo;

c) As Universidades apresentam grade curricular incompatível com as necessidades do setor produtivo e do mercado.

A Universidade deve contribuir para solucionar os problemas que surgem e o mercado de trabaIho deve absorver os conhecimentos associados à solução de problemas. Essa absorção do conhecimento gerado no decorrer dos trabalhos, em muitas situações, deve ser o fator decisivo para o sucesso desse relacionamento.

Entende-se que a questão não é se submeter às exigências do mercado de trabalho e sim trocar informações para que ambos os lados cheguem a um padrão satisfatório de exigência e qualidade dos novos profissionais. O acompanhamento sistemático de egressos pode contribuir com tal relacionamento. Uma vez que o fluxo de informações é estabelecido, faz-se um ajustamento e uma ampliação contínua das relações Universidade/ Empresa.

\section{METODOLOGIA}

Como o objetivo desta pesquisa é o de discutir e explicar a relação entre a qualidade da gestão do ensino e a importância do desenvolvimento de sistemas de acompanhamento de egressos, foi necessário proceder-se a verificações empíricas no que tange às percepções e motivações dos dirigentes de Instituições de Ensino Superior, particularmente dos cursos de Ciências Contábeis, a fim de se conseguirem elementos da realidade que pudessem compor a descrição e compreensão do fenômeno sob investigação.

\subsection{Sujeitos da pesquisa}

Os sujeitos da investigação foram os dirigentes de IES da região do Vale do Itajaí e de São Paulo. Entende-se por dirigentes aqueles profissionais que ocupam cargos de direção, coordenação ou próreitorias.

Através de uma amostragem, na qual, segundo Martins (2000), o investigador dirige-se, intencionalmente, a grupos de elementos dos quais deseja saber a opinião, foram escolhidos dirigentes das seguintes instituições: Fundação Educacional de Brusque - FEBE, Fundação Educacional Unificada do Oeste de Santa Catarina - UNOESC, Fundação Escola de Comércio Álvares Penteado - FECAP, Fundação Universidade Regional de Blumenau - FURB, Ponti- fícia Universidade Católica de São Paulo - PUC-SP, Universidade da Região de Joinville - UNIVILLE, Universidade de São Paulo - USP, Universidade do Vale do Itajaí - UNIVALI, Universidade para o Desenvolvimento do Alto Vale do Itajaí - UNIDAVI.

Entendeu-se pertinente comparar os resultados de dois Estados, Santa Catarina e São Paulo, podendo-se confrontar opiniões e percepções de dirigentes escolares das duas regiões.

\subsection{Técnica de pesquisa e instrumento para coleta de dados}

A coleta dos dados e informações foi efetuada através de entrevistas em profundidade, conduzidas pela pesquisadora.

Segundo Martins (2000), o campo de investigação, bem como o problema objeto da pesquisa, freqüentemente, limitam o tipo de instrumento que pode ser utilizado para a coleta de dados. $O$ fato de as questões estarem ligadas diretamente tanto à percepção e opinião do entrevistado, quanto ao sistema de acompanhamento de egressos e qualidade dos cursos, indicaram a opção por entrevistas.

A técnica de entrevista em profundidade, segundo Martins e Lintz (2000), é um trabalho de coleta mais demorado e preciso, e seu objetivo básico é entender o significado que os entrevistados atribuem a questões e situações em contextos que não foram estruturados anteriormente com base nas suposições e conjecturas do pesquisador.

As entrevistas foram efetuadas pela própria pesquisadora, na intenção de garantir a qualidade do trabalho de campo e regularidade de tratamento dado a todos os participantes. Foram gravadas, com a autorização dos entrevistados.

Um roteiro de entrevista semi-estruturado foi elaborado e aplicado aos dirigentes das Instituições de Ensino Superior escolhidas. A elaboração do instrumento teve como objetivo a obtenção das percepções e opiniões acerca do sistema de acompanhamento de egressos e qualidade de ensino, e sua confecção foi orientada pelo referencial teórico.

$\mathrm{O}$ instrumento de coleta é composto de três blocos de questões. O primeiro bloco é formado por dados de identificação do entrevistado e da Instituição que representa. $O$ segundo aborda o tema objeto de estudo "acompanhamento de egressos", no qual o entrevistado pode demonstrar sua familiaridade a respeito do assunto e emitir suas opiniões. $\mathrm{O}$ terceiro bloco aborda aspectos ligados à qualidade do ensino, no qual a pesquisadora procura identificar os critérios utilizados pelos dirigentes para se fazerem "medições da qualidade" e quais os impactos sobre os avaliados. 


\section{APRESENTACCÃO DOS RESULTADOS E ANÁLISES}

\subsection{Nível de conhecimento sobre pesquisas com egressos}

Dos dezenove dirigentes entrevistados, treze afirmaram conhecer o tema tratado há mais de cinco anos. Os demais há menos de cinco anos.

Esse tempo de conhecimento, supostamente, está relacionado ao tempo de trabalho de cada um como gestor, assim como aos trabalhos que as Instituições a que estão vinculados realizam a respeito do tema.

De todas as IES pesquisadas, apenas duas ainda não tiveram nenhum tipo de experiência com egressos, mas afirmaram estar em implantação. As demais já fizeram algum tipo de estudo, seja por iniciativa da própria Instituição ou por iniciativa de alunos via projeto de estágio, ou Trabalho de Conclusão de Curso.

Um depoimento interessante foi o de um dos dirigentes da FEBE. No ano de 2001, uma aluna realizou um Trabalho de Conclusão de Curso sobre como estariam os egressos do Curso de Ciências Contábeis da FEBE no mercado de trabalho. A pesquisa, segundo o dirigente, causou um impacto muito favorável entre o corpo docente e discente, assim como no grupo gestor. A IES pôde tomar conhecimento de uma realidade nunca antes pesquisada, 0 que serviu como impulsionador dos trabalhos com os egressos que ora se iniciam na Instituição.

Apenas duas, das IES pesquisadas (FECAP e FEA-USP), já têm esse tipo de estudo de forma sistemática.

Os dirigentes da UNIVALI, que estavam diretamente envolvidos nas pesquisas com os egressos, afirmaram que a não continuação dos trabalhos se deu em razão de se elegerem outras prioridades.

A UNIVILLE realizou sua pesquisa com egressos no ano de 1999 e, segundo o dirigente envolvido, a principal dificuldade foi a localização dos egressos, por conta disso o retorno da pesquisa foi muito pequeno, fazendo com que alguns coordenadores não "acreditassem" nos resultados.

Já, na FEBE, está em processo de implantação e, segundo um dos dirigentes entrevistados, ainda não foi definida a freqüência de aplicação dessa pesquisa.

A FURB fez uma pesquisa com egressos no ano de 1998. Existe a intenção de se repetir, mas ainda não se definiu uma data. Segundo um dos dirigentes envolvidos, a grande dificuldade é a de localização dos egressos e de não existir um serviço institucionalizado.
A UNOESC - Joaçaba já realizou duas pesquisas com os egressos dos cursos de Ciências Contábeis, com um intervalo de cinco anos entre uma e outra. A idéia, segundo o dirigente, é a de sistematizar esse estudo, com um intervalo de três anos entre uma pesquisa e outra. A principal dificuldade encontrada, também, é a de localização dos egressos, em função das mudanças de endereço ao término do curso.

Nota-se um problema generalizado no que se relaciona à localização do egresso. Acredita-se que isso ocorra em função da falta de tradição no que se relaciona a estudo de egressos. Não há um costume dos formados em encaminhar seus novos endereços para a IES, justamente por não existir tradição nesse relacionamento.

\subsection{Metodologias utilizadas para estudos sobre egressos}

Das IES que fizeram pesquisas com egressos, apenas a FECAP não utilizou a modalidade cartaresposta comercial pré-postada. A metodologia utilizada foi a de encaminhar uma correspondência aos ex-alunos solicitando que acessassem o site da Instituição e respondessem, on-line, ao questionário. O dirigente não soube precisar o percentual de respostas, mas garantiu que é elevado.

Nas demais IES, todas utilizaram a modalidade carta-resposta comercial pré-postada. O grande problema enfrentado é o baixo índice de devolução do instrumento, ou por problema de localização ou por falta de interesse do ex-aluno em contribuir.

$\mathrm{Na}$ visão de um dos dirigentes da UNIVILLE, mesmo que o processo apresente um retorno abaixo do esperado, é válido, pois os poucos que responderam têm algo a dizer e precisam ser ouvidos.

$\mathrm{Na}$ FEBE, a metodologia ainda não está totalmente definida. Segundo o dirigente entrevistado a tendência é que se faça questionário via correio, com envelope para devolução pré-pago. Inicialmente, pensou-se em fazer via e-mail, só que isso se tornou inviável pelo fato de a Instituição não ter as informações cadastradas. A alternativa via telefone, também, foi descartada em razão do tempo necessário.

\subsection{Avaliação das pesquisas com egressos}

Todos os dirigentes entrevistados afirmaram que consideram de grande importância para as IES pesquisas com egressos, coadunando com a visão de Both (1999), quando afirma que a avaliação da Universidade feita por ex-alunos é um dos componentes de fundamental importância, tendo em 
vista estarem percebendo a real contribuição que o curso propiciou a eles para o desempenho de suas funções do dia-a-dia.

Uma característica importante encontrada é a preocupação entre o relacionamento Universidade/ Mercado de trabalho, não como uma forma de submissão, mas sim de um trabalho integrado. Depoimento interessante de um dos dirigentes entrevistados da USP:

Acho que temos que estar muito ligados ao mercado. Ou nós estamos sintonizados com as necessidades deste objeto de estudo ou esquece, fecha a universidade. Tecnologia da informação é importante? Vamos dar isso para o nosso aluno. Ética é importante? Vamos ensinar ética[...] e assim por diante. Mas infelizmente tem coisas que não conseguimos antecipar. Penso que devemos ter um pluralismo, ou seja, você está conectado, mas não termos uma submissão, ou o compromisso de obedecer. Esta é a grande vantagem da USP, nós estarmos abertos ao aprendizado e termos chance de definir o nosso caminho. (informação verbal'1).

Os dirigentes foram unânimes com relação à importância de um sistema de acompanhamento de egressos, cujas informações podem proporcionar um quadro fiel de inserção do egresso no mundo do trabalho, permitindo, também, além da revelação da situação profissional na sua atividade, conhecer de modo significativo o perfil da formação que a escola oferece, para que uma avaliação permanente da atividade pedagógica seja feita.

No tocante à avaliação feita pelo egresso, um dado que chamou atenção nos depoimentos foi a questão da maturidade. Para os dirigentes, as avaliações dos egressos são muito diferentes daquelas enquanto alunos, no tocante à seriedade e maturidade:

Depois que eles saem da Instituição, eles não tem esta mesma visão de agora enquanto acadêmicos, de que devem detonar com tudo isso aqui, felizmente eles acabam amadurecendo, e aí vão dar a devida importância à avaliação da Instituição e do curso. Então eu acho que realmente é importante rever a questão da utilização dos dados dos egressos. (informação verbal'2).
Ouvir o egresso e conhecer sua opinião, depois que ele se desvincula da Universidade e esquece um pouco os vínculos afetivos, e passa a ter um olhar com um certo amadurecimento, com uma certa sabedoria, refletindo o que passou, é muito importante para a Instituição. (informação verbal ${ }^{3}$ ).

Quando o aluno está aqui e você vai conversar com ele, ele vai malhar o curso. Quando ele sai do curso, você conversa com ele e ele tem outra visão. $O$ fato de eu ir buscar este cara depois dele ter saído é excelente, porque ele vai ter uma visão diferente, mais madura. (informação verbal ${ }^{4}$ )

Nota-se a preocupação com a realização de uma avaliação séria, ou seja, um feedback que possa, efetivamente, sugerir mudanças de comportamentos e padrões. Entende-se que os egressos tornam-se mais independentes em relação ao seu próprio aprendizado e mais capazes de cooperar de modo efetivo.

\subsection{Ações empreendidas a partir dos resultados das pesquisas com egressos}

Das IES pesquisadas, apenas a FECAP, efetivamente, empreendeu ações a partir dos resultados de suas pesquisas com os egressos. Segundo o dirigente envolvido, houve alterações com relação à grade curricular: remanejamento de disciplinas e enfoques nos conteúdos programáticos. A principal mudança foi com relação à disciplina de Controladoria, que, geralmente, só é dada nos últimos anos. Detectaram, a partir da primeira pesquisa, que existia uma necessidade grande de profissionais e conhecimentos nessa área. Passaram a ofertá-la a partir do primeiro ano:

A mudança de nossa estrutura curricular foi baseada nestas pesquisas, ou seja, exatamente com nossa preocupação com estas pessoas no mercado de trabalho. Pessoalmente acho que estas pesquisas são especialmente válidas e necessárias, para a Instituição ter como um guia para ajustar a sua grade curricular. (informação verbal $)^{5}$.

Os dirigentes da UNIVALI afirmaram que pouco conhecem sobre a realidade dos seus egressos.

\footnotetext{
${ }^{1}$ Dirigente da USP-SP.

${ }^{2}$ Dirigente UNIVALI-SC.

${ }^{3}$ Idem.

${ }^{4}$ Dirigente USP-SP.

${ }^{5}$ Dirigente FECAP-SP.
} 
Houve o apontamento da necessidade de se efetuarem novas pesquisas:

Sabemos da necessidade de se realizar uma nova pesquisa, obtendo assim um feedback não só da sua inserção no mundo do trabalho, e como cidadão, mas também um feedback ao curso de como foi a sua formação. Então os resultados de uma pesquisa sobre os egressos nos traz indicativos tanto para serem apresentadas novas alternativas de cursos dentro da Instituição como rever a própria matriz curricular e organização dos cursos em oferta. Acho que é fundamental a opinião do egresso. (informação verbal ${ }^{6}$ ).

O dirigente afirma que as pesquisas com os egressos acabam sendo realizadas de maneira informal, através dos contatos feitos em seminários, semanas acadêmicas e no seu regresso nos cursos de especialização mantidos pela UNIVALI. O tema dessas entrevistas informais gira em torno de vários aspectos do curso de graduação, pontos fortes e fracos, corpo docente, currículo, ementas das disciplinas, e onde, na visão do egresso, a Universidade "pecou" no processo de ensino. Essas questões são, então, repassadas ao corpo docente, em reuniões pedagógicas e, na medida do possível, algumas alterações são efetuadas nas ementas das disciplinas.

O dirigente entrevistado da UNIVILLE afirmou que os coordenadores de curso não efetuaram nenhuma ação com base no relatório da pesquisa com os egressos:

Alguns coordenadores nem sequer olharam os relatórios e têm como defesa o percentual de devolução que foi baixo. É muito mais fácil ficar no espaço estável do que ter que ouvir. Acho que 112 alunos tinham coisas a dizer da Universidade, mas para eles isto foi pouco. (informação verbal ${ }^{7}$ ).

Para subsidiar a tomada de decisões, os resultados das pesquisas devem proporcionar mudanças e correções dos problemas que prejudicam o desempenho do curso e da Instituição. O conhecimento dos resultados deve produzir um processo de autocrítica, fazendo com que haja motivação e desejo de mudar a situação. Nessas condições, os resultados devem ser utilizados como subsídios para promover as mudanças necessárias. Na visão de Souza (1999), a avaliação deve ser planejada, conduzida e realizada tendo em mente que seus resultados serão úteis para os interessados. Os resultados devem estar disponíveis para todos e nenhum dado deve ser omitido, até para que se justifiquem os esforços e recursos financeiros envolvidos no processo.

\subsection{Nível de aptidão dos egressos para o trabalho}

Quando questionados sobre o nível de aptidão para o trabalho, a maioria afirmou que os egressos saem da Instituição "aptos com poucas restrições".

$\mathrm{Na}$ visão de alguns dirigentes, o que falta, ainda, para os alunos é o desenvolvimento da parte prática. Apesar de a maioria das Instituições trabalharem com o chamado Laboratório Contábil, as simulações existentes, ainda, não são suficientes para atingir a qualificação necessária.

Segundo Marion (2001), as aulas práticas deveriam ser aplicadas em quase todas as disciplinas dos cursos de Ciências Contábeis, sendo direcionadas como complemento às aulas teórico-expositivas. Esse método consiste em mostrar aos alunos o lado prático da disciplina.

Já alguns dirigentes são mais enfáticos, dizendo não ser possível fazer com que o aluno saia totalmente apto para o mercado de trabalho:

É impossível formar um indivíduo, com substancial conhecimento teórico e deixá-lo pronto para o mercado de trabalho. Muita coisa, a própria experiência, o próprio envolvimento no mercado é que vai ajudar na sua formação. Eu entendo que não existe um profissional totalmente apto, perfeito, acabado. O processo de formação do conhecimento é longo e permanente, segue sempre em busca do conhecimento, das informações, pois tanto a dinâmica do mercado, quanto dos processos de informação, é muito rápida, e isto faz com que haja uma necessidade constante de atualização. (informação verbal ${ }^{8}$ ).

Essa visão coaduna com Franco (1993), que afirma que a Contabilidade exige de seus profissionais uma constante atualização e complementação de conhecimentos, buscando a capacidade de acompanhar a constante evolução da técnica e da economia em geral. 
Dos dirigentes entrevistados, dois afirmaram que consideram seus egressos totalmente aptos para o mercado de trabalho:

Os alunos da FECAP estão totalmente aptos, porque o projeto pedagógico do Curso está enraizado em três fundamentos: diretrizes do MEC, Missão da IES e o mercado de trabalho. Estamos sempre olhando o mercado e incorporando em nossa grade os fundamentos necessários para atendermos a isto. (informação verbal ${ }^{9}$ ).

Temos uma característica muito forte que é em auditoria, existe uma ligação inclusive de convênios com empresas de auditoria conosco. Então temos, de uma certa forma, um acompanhamento e um desenvolvimento constante do aluno, pois precisamos fazer relatórios, eles têm bolsas, então você tem que estar tomando ciência o tempo inteiro do acompanhamento do aluno. Então isso obriga uma seriedade maior do aluno para com o curso também, então acabamos verificando que eles estão totalmente aptos para enfrentarem este mercado. (informação verbal ${ }^{10}$ ).

\subsection{Indicadores de aferição da qualidade}

Detectou-se que, para a maioria das IES, o indicador principal utilizado é o programa interno de avaliação institucional.

$\mathrm{Na}$ UNIVALI, essa avaliação é realizada pelo corpo discente com relação a vários aspectos, entre eles o desempenho dos professores, a estrutura de acompanhamento didático-pedagógico e a estrutura física da Instituição. O corpo docente, também, faz uma avaliação com relação à infra-estrutura, serviços de apoio ao curso e desempenho dos alunos. São utilizados questionários e a pesquisa é realizada anualmente.

$\mathrm{Na}$ FEBE, a Avaliação Institucional é realizada semestralmente com a participação do corpo docente e discente. No segundo semestre do ano de 2002, foi implantada a avaliação on-line: os alunos e professores responderam ao questionário na intranet da Instituição, em um determinado dia da semana, agilizando o processo.

Note-se que, para as Instituições pesquisadas, o programa de avaliação institucional se constitui num elemento de importância para a gestão, pois afere e compatibiliza as visões de qualidade dos segmentos envolvidos, preparando as bases para o planejamento institucional.

Já para os dirigentes da PUC-SP e FEA-USP, o principal indicador de qualidade se dá através do acompanhamento constante dos processos de ensino.

Na PUC fazemos um acompanhamento constante. Temos reuniões departamentais de no mínimo três por semestre. Então este acompanhamento é constante. A par disso você tem um entrosamento muito grande na equipe de professores, então você tem as linhas de disciplinas afins. Os professores mesmo entre eles se reúnem para verificar programas, porque às vezes você tem salas que rendem maravilhosamente bem, mas você tem, às vezes, turmas que não têm o mesmo rendimento ou não têm o rendimento esperado, então aquele professor comunica imediatamente o outro da seqüência, então temos um remanejamento constante. Não há um isolamento acadêmico, a equipe trabalha muito coesa, e isso é fundamental. É nosso principal indicador. (informação verbal ${ }^{11}$ ).

Na verdade o primeiro indicador são os resultados das provas que nós temos durante o curso. Os professores também percebem isso e de maneira geral vai se materializando em todas as disciplinas. Então à medida que os alunos vão fazendo as disciplinas e tendo as suas avaliações, isso vai se tornando meio que público. Então já se começa a fazer uma diferença entre os alunos classe $A$, os que são muito bons, aquela massa de alunos na média e tem aqueles também que são muito ruins, eventualmente também pode acontecer. Então a avaliação durante o processo, eu considero a mais importante. (Informação verbal ${ }^{12}$ ).

Constatou-se, também, que os dirigentes das IES pesquisadas utilizam os resultados do Exame Nacional de Cursos e do Exame de Suficiência do CFC como indicadores de qualidade, ressalvadas algumas restrições mostradas a seguir.

\subsubsection{Utilização do resultado do Exame Nacional de Cursos como indicador de qualidade}

Os dirigentes entrevistados foram unânimes em afirmar que utilizam os resultados do ENC como

\footnotetext{
${ }^{9}$ Dirigente da FECAP-SP

${ }^{10}$ Dirigente da PUC-SP.

${ }^{11}$ Dirigente da PUC-SP.

${ }^{12}$ Dirigente da USP-SP.
} 
um indicador de qualidade dos cursos de graduação, e se posicionaram a favor, porém alguns apresentaram restrições:

O Exame Nacional de Cursos também deve ser considerado, mas com as devidas restrições. Há o problema do não comprometimento do aluno com o resultado do exame. Muitos alunos saíram no tempo mínimo, encerrado o tempo mínimo para permanência em sala, muitos foram embora. Demonstraram claramente que não estavam comprometidos com o processo. (informação verbal $\left.{ }^{13}\right)$.

A questão do "compromisso" do aluno ao realizar a prova é um aspecto que preocupa os dirigentes das Instituições. Críticas são feitas com relação a isso. Linhares (2002) discorre que, se o aluno entregar a prova em branco ou "chutar" as respostas das questões, nada acontece para ele. $O$ que se cobra é apenas a assinatura na lista de presença, sob pena de não receber seu diploma. A nota média obtida pelos alunos formandos vai para o curso que freqüentaram e a Instituição que o mantém.

Na visão de Catani (2001), a gestão universitária acaba sendo moldada por uma lógica baseada no desempenho dos resultados obtidos. Os currículos e as ações didático-pedagógicas no interior dos cursos vão se subordinando aos parâmetros de avaliação externos.

Apesar das críticas, muitas melhoras já ocorreram nos cursos em função da participação das turmas nesse primeiro ENC para Ciências Contábeis:

Acho que estamos passando por uma fase de transição muito grande, inclusive no processo de gestão, e o Provão é um grande divisor de águas, ele pode não ser o melhor instrumento, mas já é um instrumento de mudanças. Só isso já justifica sua existência. De qualquer forma ele traz uma preocupação para as IES, mas como todo processo de avaliação, ele precisa ser aprimorado. Assim como o ensino não é um processo fechado e não se completa nunca, o processo de avaliação também. (informação verbal ${ }^{14}$ ).

Ressalvadas algumas restrições, a totalidade dos dirigentes afirma que o Provão deve continuar, um depoimento, que resume essas visões, é o seguinte:
Se o exame não é bom, você pode melhorar. Se ele é muito específico, você pode torná-lo mais abrangente, se for muito abrangente você pode torná-lo mais específico. Acredito que é uma medida excepcional. (informação verbal ${ }^{15}$ ).

\subsubsection{Utilização do resultado do Exame de Suficiência do Conselho Federal de Contabilidade como indicador de qualidade}

A grande maioria dos dirigentes entrevistados afirmou que os resultados do Exame de Suficiência do CFC, também, podem servir como um indicador de qualidade, desde que ressalvadas algumas questões que muito se assemelham às restrições feitas ao ENC:

Atualmente a nossa instituição acaba utilizando os resultados como um dos instrumentos de avaliação do curso, mas para ser mais calibrado e apresentar resultados confiáveis, algumas correções devem ser implementadas. A primeira prova realizada, pela análise que o nosso corpo docente fez, revelou que as questões estavam muito aquém do que se esperava como um instrumento de avaliação. Não sei se por ser a primeira, ou o pessoal estava testando ainda o instrumento, mas a partir da segunda prova, vimos que houve um rigor mais acentuado, que as questões se apresentaram mais bem elaboradas e condizentes com uma avaliação abrangente e generalizada. (informação verbal ${ }^{16}$ ).

Eu acho ótimo também. Não estou entrando no detalhe da avaliação. Não estou dizendo que eles estão sendo feitos, formatados da melhor maneira possível. Mas não tenho muitas críticas a eles não. Mas de qualquer maneira existe o mérito extrínseco no instrumento. Quando você faz uma avaliação, por menos rigorosa que ela seja, ela já discrimina pelo menos um pedaço da população que não tem a menor condição. (informação verbal ${ }^{17}$ ).

Dois dirigentes se posicionaram radicalmente contra esse tipo de avaliação. Entendem que, se o aluno esteve por um período de quatro ou cinco anos dentro de uma IES e essa Instituição Ihe entregou o diploma, significa que ele já pode atuar

\footnotetext{
${ }^{13}$ Dirigente da FEBE-SC.

${ }^{14}$ Dirigente da PUC-SP.

${ }^{15}$ Idem.

${ }^{16}$ Dirigente da UNIVALI-SC.
} 
no mercado de trabalho, independente de qualquer tipo de avaliação realizada por órgãos de classe:

Sou contra este tipo de exame. Acho que o Conselho deveria fazer um trabalho com as Instituições de Ensino e não com os alunos. Ver onde está o problema, seja com os professores, seja com a Instituição em si, e não com os alunos. (informação verbal'18).

É um exame equivocado para qualificar a universidade de forma a vincular a imagem da instituição. A questão do prazo para se realizar a prova é complicada, pois se o aluno não faz logo que saiu, muita coisa ele esquece. Quem sabe um dia chegamos num ponto em que a Instituição não precise mais certificar o aluno, já que os Conselhos o fazem? Do jeito que está hoje, é difícil, pois a Universidade dá o Diploma, e o Conselho o desabilita de exercer a profissão. $O$ exame de ordem é um instrumento muito poderoso. (informação verbal ${ }^{19}$ ).

Outro dirigente que se posicionou contra o Exame de Suficiência, da maneira como está atualmente, foi o da PUC-SP:

Eu acho que não serve como indicador de qualidade. Inclusive estou fazendo um estudo grande contrapondo os resultados do Exame de Suficiência com os resultados do Provão. Estou fazendo uma pesquisa no Brasil inteiro. Acho que não cabe ao Exame de Suficiência avaliar se o aluno sabe português ou matemática, isto o Provão faz. Quem vai examinar o conteúdo programático é o Provão, porque o MEC é quem está examinando. O Exame de Suficiência tem que examinar os conhecimentos contábeis, porque é o contador que ele vai credenciar. Ao CFC compete saber se a pessoa tem condição de fazer o exercício profissional, então ele tem que demonstrar que conhece realmente, que está apto a desenvolver o trabalho contábil. A exemplo do que é feito lá fora como o AICPA. Tem capacitação profissional? Ele vai ter que demonstrar em conhecimentos contábeis. (informação verbal ${ }^{20}$ ).

\section{CONSIDERAÇÕES FINAIS}

Através da pesquisa, constatou-se um reconhecimento por parte dos dirigentes das IESs sobre a necessidade de institucionalização da prática do acompanhamento dos egressos nos cursos de Ciências Contábeis. Segundo os dirigentes entrevistados, a utilidade desse tipo de estudo é a de estabelecer e definir uma interação sistematizada entre as IES e seus egressos.

A observação da trajetória dos ex-alunos serve como fonte de informações gerenciais, permitindo a tomada de decisões sobre o planejamento de cursos, arranjos didático-pedagógicos e modalidades de programas que desenvolvam uma polivalência e identidade profissional capazes de interagir e de atender às mutações do mercado de trabalho. À medida que não existe uma sistemática consolidada de acompanhamento dos egressos, não há meio de saber se as IES cumprem bem seu papel de prepará-los para a realidade profissional. Nota-se que as IES pesquisadas, realmente, não têm conhecimento preciso sobre a qualidade dos profissionais que ofertam ao mercado de trabalho, pelo menos de maneira formal.

Toda proposta de melhoria da qualidade requer a produção de informações relevantes sobre o desempenho institucional. A construção de um sistema de acompanhamento de egressos constitui uma ferramenta para se estabelecer e desenvolver estratégias para melhoramento da gestão. Sendo assim, a primeira utilidade desse tipo de estudo está relacionada com os gestores das IES. Esses profissionais necessitam de informações tempestivas e pertinentes sobre o desempenho dos seus egressos, o que permite, se necessário, a introdução de modificações em seu modo de agir, reorientando suas ações.

Avaliar o desempenho do ex-aluno, utilizando-o como um indicador de qualidade, através do resultado do ENC e do Exame de Suficiência do CFC, não é tão simples quanto parece. Segundo os próprios dirigentes, esse desempenho pode estar relacionado com outras variáveis, como, por exemplo, comprometimento do aluno com a realização dos exames, elaboração das questões e do tipo de relacionamento que ele teve com a Instituição durante a sua vida acadêmica.

Nesse sentido, nota-se a necessidade de se criar uma cultura de avaliação, no que se relacio-

\footnotetext{
${ }^{17}$ Dirigente da USP-SP.

${ }^{18}$ Dirigente da FEBE-SC.

${ }^{19}$ Dirigente da FURB-SC.

${ }^{20}$ Dirigente da PUC-SP.
} 
na aos egressos. A adesão à avaliação por parte de toda a comunidade acadêmica - professores, alunos e funcionários técnico-administrativos - é extremamente importante para o sucesso da organização. Essa cultura deve começar a ser formada nos primeiros anos em que os alunos ingressam no curso. A prática sistemática do acompanhamento de egressos nas IES requer uma mudança de mentalidade, uma nova cultura voltada para a eficiência, para a qualidade e para a relevância social dos resultados. Só, assim, se poderá aprender com os erros cometidos, corrigir as falhas, melhorar o desempenho institucional.

Estabelecer um canal de comunicação com os egressos implica em ouvir aqueles que pela Instituição passaram, cujas percepções, pareceres e críticas possam fundamentar projetos institucionais. É uma ferramenta gerencial que, aliada a outros indicadores, como ENC, Exame de Suficiência e processos internos de avaliação institucional, pode se constituir em um importante diferencial para que a IES atinja seus principais objetivos.

\section{REFERÊNCIAS BIBLIOGRÁFICAS}

BOTH, Ivo José. Avaliar a universidade é preciso: agente de modernização administrativa e da educação. In: SOUZA, Eda C. B. Machado (org). Avaliação Institucional. 2. ed. Brasília: Universidade de Brasília, 1999. 244 p.

CATANI, Afrânio Mendes. A Política de avaliação da educação superior no Brasil em questão. Revista Avaliação. Campinas, v. 6, n. 4, p. 7-15, 2001.

FRANCO, Hilário. Formação educacional e profissional do contador. Revista Brasileira de Contabilidade, Brasília, DF, n. 82, mar/abr 1993.

FRANCO, Maria Laura P. Barbosa. Avaliação de cursos. In: SOUZA, Eda C. B. Machado (org.). Avaliação de currículos e programas. Brasília: Universidade de Brasília, 2000. 72 p.

GARCIAS, Paulo Mello. $1^{\circ}$ Concurso de monografia sobre a relação universidade empresa. Curitiba: IPARDES, 1999.

KUNZ, Ivanir. Modalidades distintas na relação universidade/ empresa e suas características específicas no Brasil. In: $1^{\circ}$ Concurso de monografia sobre a relação universidade empresa. Curitiba: IPARDES, 1999.

LINHARES, Milton. Provão: sete anos, sete erros. Revista Ensino Superior. São Paulo, n. 46, p. 44-45, 2002.

MACHADO, Antônio de Souza. Acompanhamento de egressos: caso CEFET-PR - Unidade de Curitiba. 2001. 134 p. Dissertação (Mestrado em Engenharia de Produção). Universidade Federal de Santa Catarina, Florianópolis, Santa Catarina.
MARION, José Carlos. O ensino da contabilidade. 2. ed. São Paulo: Atlas, 2001. 135 p.

MARTINS, Gilberto de Andrade. As atividades de marketing nas instituições de ensino superior. 1986. 200p. Tese (Doutorado) - Faculdade de Economia, Administração e Contabilidade, Universidade de São Paulo, São Paulo

Manual para elaboração de monografias e dissertações. São Paulo: Atlas, 2000. 116 p.

MARTINS, Gilberto de Andrade; LINTZ, Alexandre. Guia para elaboração de monografias e trabalhos de conclusão de curso. São Paulo: Atlas, 2000. 108 p.

MEHEDFF, Nassim Gabriel. A avaliação da educação e a inserção dos egressos do ensino médio no mercado de trabalho. Brasília: Instituto Nacional de Estudos e Pesquisas Educacionais, 1999, 17 p.

SCHWARTZMAN, Simon; CASTRO, Maria Helena de Magalhães. A trajetória acadêmica e profissional dos alunos da USP. Documento de Trabalho 2/91. São Paulo: Núcleo de Pesquisas sobre o ensino superior da Universidade de São Paulo, 1991.

SOUZA, Eda C. B. Machado de. Avaliação de instituições de ensino superior: o caso do Brasil e de outros países. 2. ed. Brasília: Universidade de Brasília, 1999. 110 p.

STAINSACK, Shellen. A Interação universidade/empresa no Estado do Paraná. In: $1^{\circ}$ Concurso de monografia sobre a relação universidade/empresa. Curitiba: IPARDES, 1999.

\section{NOTA:}

Endereço dos autores:

Ana Cristina Zenha Lousada

Universidade do Vale do Itajaí

R. Uruguai, 458 - Campus Universitário

Centro -Tijucas - SC

88302-202

Gilberto de Andrade Martins

Universidade de São Paulo

Av. Prof. Luciano Gualberto, 908 - prédio 3

Campus Capital - São Paulo - SP

05508-900 